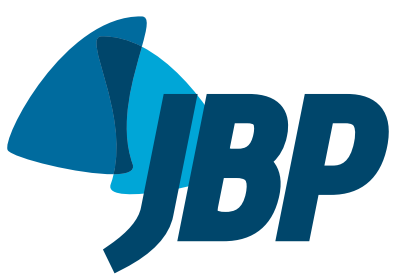

\title{
Pulmonary foreign body granulomatosis in a chronic user of powder cocaine
}

\author{
Shruti Khurana', Ankit Chhoda², Sandeep Sahay ${ }^{3}$, Priyanka Pathania ${ }^{4}$
}

1. Lady Hardinge Medical College, New Delhi, India.

2. Maulana Azad Medical College, Department of Internal Medicine, New Delhi, India.

3. Houston Methodist Lung Center, Houston (TX) USA.

4. Jack C. Montgomery VA Medical Center, Department of Pulmonary Medicine, Muskogee (OK) USA.

Submitted: 1 September 2016 Accepted: 31 October 2016.

Study carried out at the Houston Methodist Lung Center, Houston (TX) USA

\begin{abstract}
We describe the case of a 33-year-old man, a chronic user of powder cocaine, who presented with dyspnea, fever, night sweats, and significant weight loss. Chest HRCT revealed centrilobular nodules, giving an initial impression of miliary tuberculosis. Therefore, he was started on an empirical, four-drug antituberculosis treatment regimen. Four weeks later, despite the tuberculosis treatment, he continued to have the same symptoms. We then performed transbronchial lung biopsy. Histopathological analysis of the biopsy sample revealed birefringent foreign body granuloma. A corroborative history of cocaine snorting, the presence of centrilobular nodules, and the foreign body-related histopathological findings led to a diagnosis of pulmonary foreign body granulomatosis. This report underscores the fact that pulmonary foreign body granulomatosis should be included in the differential diagnosis of clinical profiles resembling tuberculosis.
\end{abstract}

Keywords: Lung; Granuloma, foreign-body; Cocaine-related disorders.

\section{INTRODUCTION}

Physicians frequently encounter cocaine abuse in clinical practice. It is the leading cause of illicit drug-related deaths worldwide. (1) Cocaine is abused by multiple methods, the snorting of powder cocaine being the most common. Pulmonary complications, such as alveolitis, barotrauma, talcosis, organizing pneumonia, bullous emphysema, and pulmonary fibrosis, are frequently reported as a result of crack cocaine smoking or intravenous cocaine use. (2) However, there has been only one report to date of pulmonary foreign body granulomatosis (PFBG) secondary to cocaine snorting. ${ }^{(3)}$

\section{CASE REPORT}

A 33-year-old Hispanic male of average build was admitted to our facility, complaining of dyspnea, fever, night sweats, and rapid weight loss (18 kg over a fourmonth period). A pertinent positive finding on the initial history taking was his having traveled to a country where tuberculosis is endemic. Physical examination revealed no acute distress and no stigmata of intravenous drug abuse. He was febrile $\left(\leq 38.5^{\circ} \mathrm{C}\right)$, with a blood pressure of $124 / 72 \mathrm{mmHg}$, a heart rate of $76 \mathrm{bpm}$, a respiratory rate of 18 breaths/min, and a constant $\mathrm{SpO}_{2}$ at rest of $98 \%$. The initial total leukocyte count was 8,200 cells $/ \mu \mathrm{L}$, with a predominant neutrophilic reaction. Blood culture was negative for aerobic and anaerobic microorganisms. Urine toxicology and HIV tests were negative. Chest X-ray and HRCT showed micronodules (1-3 mm in size) bilaterally in centrilobular distribution (Figure 1). An IFN- $y$ assay and sputum smear microscopy for acid-fast bacilli were carried out in order to rule out mycobacterial infection. Although the results were negative for tuberculosis, the high clinical suspicion of the disease prompted empirical initiation of the four-drug antituberculous therapy. Four weeks later, the patient returned to the emergency room with worsening of the shortness of breath. A repeat HRCT revealed similar centrilobular nodules with no radiological improvement (Figure 2). At that time, bronchoscopy with transbronchial lung biopsy was performed for further evaluation of the pulmonary micronodules. Examination of the BAL fluid, with Ziehl-Neelsen staining, revealed no acid-fast bacilli. Histopathological analysis of the transbronchial lung biopsy specimen showed multiple granulomas with birefringent material in the center (Figure 3), confirming the diagnosis of PFBG. The patient strongly denied intravenous drug use. Unfortunately, he experienced a progressive course with a further decline in his lung function. After progressive fibrosis over the following one-year period, the patient died of chronic respiratory failure.

\section{DISCUSSION}

The lungs are frequently affected by cocaine abuse, regardless of the delivery method. Clinical presentation and radiological findings are varied and highly nonspecific. ${ }^{(4)}$ PFBG is a rare condition, and its true incidence is unknown. It is commonly encountered secondary to intravenous injection of pulverized pharmaceutical tablets containing insoluble binders, such as talc, cellulose, starch, and other street adulterants. The tiny particles lodge in the vascular bed and interstitium to cause granulomatous reactions and fibrosis. ${ }^{(5)}$ Prior to this report, there had been only one reported case of PFBG in a user of powder cocaine (intranasal route), which was determined to be caused by cellulose filler. ${ }^{(3)}$ Radiologically, PFBG can present as small diffuse centrilobular nodules, conglomerated masses, diffuse ground-glass opacities, and lower-lobe

Correspondence to:

Sandeep Sahay. Houston Methodist Lung Center, Suite 1001, Smith Tower, 6550 Fannin Street, ZIP 77030, Houston, TX, USA.

Tel.: 1713 363-9587. E-mail: ssashay@houstonmethodist.org

Financial support: None. 

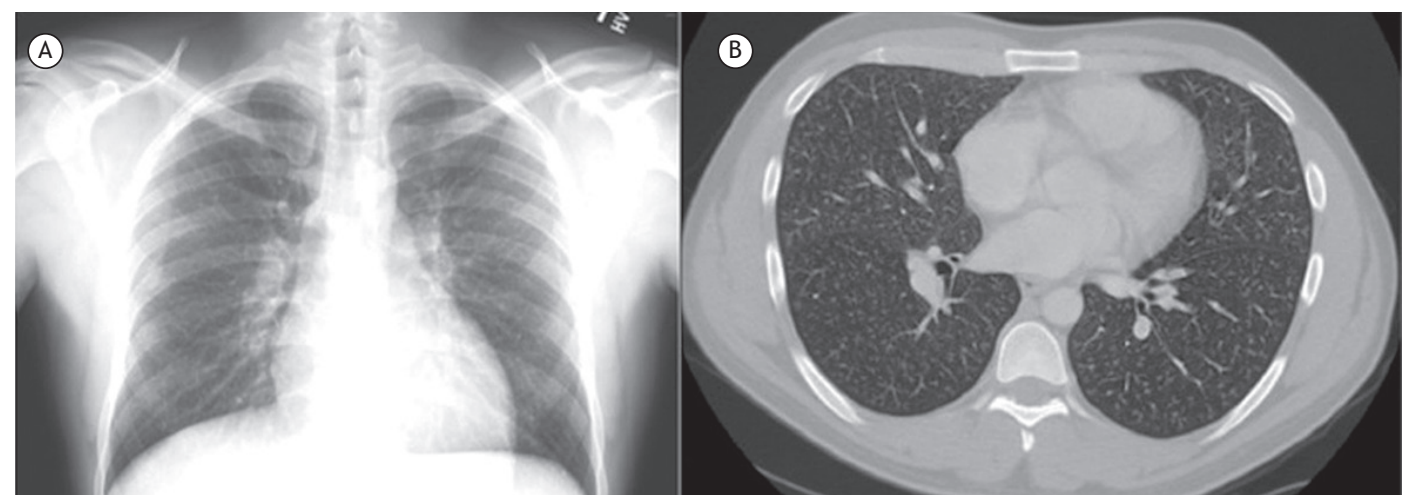

Figure 1. In A, a chest X-ray showing micronodular shadows. In $B, a C T$ scan of the chest, showing centrilobular nodules in both lung fields.

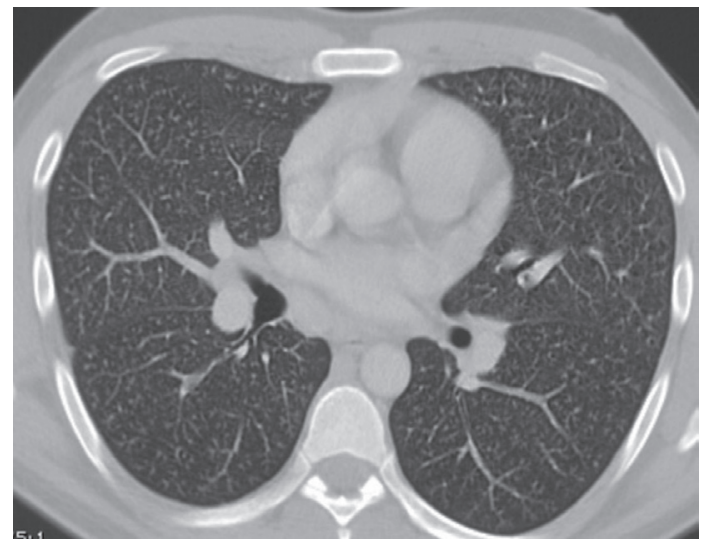

Figure 2. A CT scan of the chest showing the persistence of centrilobular nodules in bilateral lung fields after four weeks of treatment with antituberculosis drugs.

panlobular emphysema. ${ }^{(6)}$ Because our patient was inhaling cocaine, the appearance of centrilobular nodules on chest CT was consistent with small airway disease, as opposed to miliary tuberculosis, which usually presents as random nodules. It is prudent to consider rare granulomatous conditions such as PFBG in patients with a history of intravenous or inhaled drug abuse. The course of PFBG can be subacute (with fever, weight loss, or hemoptysis) or chronic (with dyspnea and a progressive decline in lung function). ${ }^{(7)}$ Late

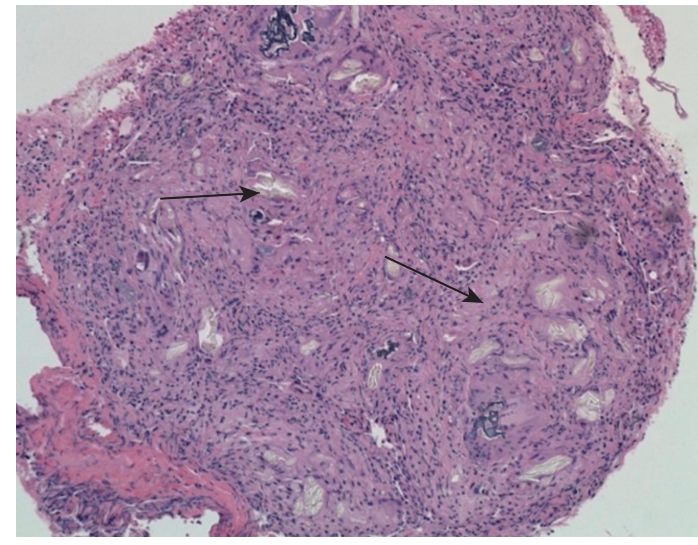

Figure 3. Photomicrograph of the transbronchial biopsy specimen (lung tissue) showing birefringent foreign body material (left arrow), together with granuloma formation (right arrow) around the foreign body material (H\&E; magnification, $\times 40)$.

complications include pulmonary hypertension, cor pulmonale, panlobular emphysema, and, rarely, respiratory failure requiring lung transplantation. ${ }^{(8,9)}$ There is no specific treatment for PFBG. A few patients have experienced stabilization of symptoms after cessation of drug use and resolution of acute symptoms with corticosteroid use. ${ }^{(10)}$ Avoidance of exposure continues to be the cornerstone of management.

\section{REFERENCES}

1. Restrepo CS, Carrillo JA, Martínez S, Ojeda P, Rivera AL, Hatta A. Pulmonary complications from cocaine and cocaine-based substances: imaging manifestations. Radiographics. 2007;27(4):94156. https://doi.org/10.1148/rg.274065144

2. Tseng W, Sutter ME, Albertson TE. Stimulants and the lung: review of literature. Clin Rev Allergy Immunol. 2014;46(1):82-100. https:// doi.org/10.1007/s12016-013-8376-9

3. Cooper CB, Bai TR, Heyderman E, Corrin B. Cellulose granuloma in the lungs of a cocaine sniffer. Br Med J (Clin Res Ed). 1983;286(6383):2021-2. https://doi.org/10.1136/ bmj.286.6383.2021-a

4. Almeida RR, Zanetti G, Souza AS Jr, Souza LS, Silva JL, Escuissato $\mathrm{DL}$, et. al. Cocaine-induced pulmonary changes: HRCT findings. J Bras Pneumol. 2015;41(4):323-30. https://doi.org/10.1590/S180637132015000000025

5. Ellis SJ, Cleverley JR, Müller NL. Drug-induced lung disease: highresolution CT findings. AJR Am J Roentgenol. 2000;175(4):1019-24. https://doi.org/10.2214/ajr.175.4.1751019

6. Marchiori E, Lourenço S, Gasparetto TD, Zanetti G, Mano CM, Nobre LF. Pulmonary talcosis: imaging findings. Lung. 2010;188(2):165-71. https://doi.org/10.1007/s00408-010-9230-y

7. Paré JP, Cote G, Fraser RS. Long-term follow-up of drug abusers with intravenous talcosis. Am Rev Respir Dis. 1989;139(1):233-41 https://doi.org/10.1164/ajrccm/139.1.233

8. Shlomi D, Shitrit D, Bendayan D, Sahar G, Shechtman Y, Kramer MR Successful lung transplantation for talcosis secondary to intravenous abuse of oral drug. Int J Chron Obstruct Pulmon Dis. 2008;3(2):32730.

9. Weinkauf JG, Puttagunta L, Nador R, Jackson K, LaBranche K, Kapasi $A$, et al. Long-term outcome of lung transplantation in previous intravenous drug users with talc lung granulomatosis. Transplant Proc. 2013;45(6):2375-7. https://doi.org/10.1016/j. transproceed.2012.11.004

10. Smith RH, Graf MS, Silverman JF. Successful management of drug-induced talc granulomatosis with corticosteroids. Chest. 1978;73(4):552-4. https://doi.org/10.1378/chest.73.4.552 